\title{
Lutas de Classes na Rússia, de Karl Marx e Friedrich Engels
}

[MARX, Karl; ENGELS, Friedrich. Lutas de Classes na Rússia. LÖWY, Michael (org.), Trad. Nélio Schneider. 1 ed. São Paulo: Boitempo, 2013, 164p.]

\section{Lucas Parreira Álvares ${ }^{1}$}

No projeto da editora Boitempo de publicar as obras completas de Marx e Engels, o ano de 2013 cumpriu um papel determinante: inicialmente com a publicação da nova tradução de O Capital, e, em seguida, com Lutas de classe na Rússia². Tal ordem de publicação possui sua justificativa devido ao fato de que grande parte da essência da obra aqui apresentada tem seus questionamentos advindos da repercussão que O Capital teve na Rússia, como poderemos observar nas anotações que se seguem.

Podemos dividir a organização da obra Lutas de Classes na Rússia em três partes: a primeira com a Literatura de Refugiados $V$, que reúne textos de Engels publicados em 1875. A motivação para esse texto se deu como uma resposta à Piotr Tkatchov ${ }^{3}$, esse que expediu, em Zurique, no ano de 1874, sua "Carta aberta ao senhor Friedrich Engels", na qual criticou veementemente um artigo de Engels na revista "Avante!"

1 Graduando em Ciências do Estado pela Universidade Federal de Minas Gerais. E-mail: lucasparreira1@gmail.com

2 Agradeço ao professor Vitor Bartoletti Sartori pelas orientações, correções e sugestões.

3 Piotr Nikitich Tkatchov (1844-1886) foi um escritor revolucionário e crítico russo.Tkatchov era considerado blanquista e "populista", e tinha como desejo um socialismo russo baseado nas comunas rurais. 
daquele ano. Para Löwy (p.7), esse texto de Engels foi uma espécie de "momento zero" correspondente ao debate desses dois autores acerca da particularidade da comuna rural na Rússia.

A segunda parte da obra podemos atribuir à Carta à redação da Otechestvenye Zapiski - relevante revista de São Petersburgo alinhada aos populistas russos - de autoria de Karl Marx, com a intenção de ser enviada à redação da revista. Esse texto, redigido em 1877, também foi motivado a partir de uma resposta, nesse caso, à Nicolai Mikhailovski ${ }^{4}$, que escreveu artigo intitulado "Marxdiante do tribunal de Ju. Jukovski ${ }^{5}$ ". Porém, Marx nunca chegou a enviar a referida carta à redação da revista ${ }^{6}$.

A terceira parte de Lutas de Classe na Rússia diz respeito ao debate de Marx com a revolucionária Vera Ivanovna Zasulitch, integrante do grupo revolucionário russo "Emancipação do Trabalho". Na edição, o texto que antecede a discussão entre os revolucionários é uma introdução produzida por David Riazanov com o título "Vera Zasulitch e Karl Marx". Riazanov cumpriu um importante papel ao marxismo por ter sido o primeiro a tentar editar as obras completas de Marx e Engels, o que fez com que ele tivesse contato não só com a carta que Marx enviara à Vera Zasulitch, como também aos rascunhos encontrados. Nos textos que seguem, são apresentadas, enfim: a carta de Vera Zasulitch a Karl Marx; os quatro esboços de Marx, bem como a versão final enviada à Vera Zasulitch; o prefácio de 1882 à edição russa do Manifesto Comunista, feito por Marx e Engels e que retoma a questão

4 Nicolai Constantinovitch Mikhailovski (1842-1904) foi sociólogo e crítico literário russo. Mikhailovski foi um dos principais nomes do movimento Narodnik - nome dado à organização dos "populistas" russos, que eram membros das elites urbanas e simpáticos ao socialismo agrário, inspirados pelo romantismo.

5 Em referência ao economista vulgar Juli Galactionovitch Jukovski, segundo a edição da MEGA-2,"um economista burguês liberal que havia feito ataques sem conhecimento de causa contra Marx a partir de O Capital, publicado na revista 'O Mensageiro da Europa', em setembro de 1877" (p.57).

6 Segundo Engels (p.58), Marx não a enviou, pois temia que devido à má repercussão de seu nome, a revista pudesse sofrer danos.

7 David Borisovich Goldendach (1870-1938), mais conhecido por David Riazanov, foi intelectual, ativista sindical, bolchevique, e diretor do Instituto Marx-Engels de Moscou. 
supracitada; e também o posfácio de Engels, já em 1894, à brochura Questões Sociais da Rússia.

Além de tudo isso, a edição possui o prefácioDialética revolucionária contra a ideologia burguesa do Progresso, escrito por Michael Löwy. Para além das polêmicas já apresentadas no texto, Löwy faz algumas provocações, desde a afirmação enfática que esses textos "significam uma ruptura profunda com qualquer interpretação unilinear, evolucionista, “' 'etapista' e eurocêntrica do materialismo histórico" (p. 9), até associar a posição de Marx e Engels a uma "dialética tipicamente romântico-revolucionária (...) inspirada pelos trabalhos de comunismo primitivo de historiadores e antropólogos (românticos! ${ }^{8}$ ) como Maurer e Lewis Morgan". Ainda que Löwy entenda que esse é um momento de ruptura do materialismo histórico de Marx e Engels, e essa é uma noção também adotada por diversos teóricos ${ }^{9}$, algumas obras que antecederam os textos sobre a questão da Rússia já demonstravam uma não adesão a essa noção "unilinear da história", como por exemplo, $A$ Ideologia Alemã, os Grundrisse e o tomo 1 de O Capital.

Além das concepções históricas, algumas outras observações também devem ser feitas:a noção de "Romantismo Revolucionário", por exemplo, é uma concepção adotada quase que exclusivamente por Löwy. O brasileiro/francês disserta com mais atenção sobre o conceito em duas de suas obras em coautoria com Robert Sayre: Romantismo e Política ${ }^{10}$, originalmente de 1989; e, já em 1992, um trabalho mais extenso chamado Revolta e Melancolia: o romantismo na contracorrente da Modernidade ${ }^{11}$. Nessa segunda obra, os autores conceituam o chamado "Romantismo Revolucionário" como uma ideia que recusa tanto uma "ilusão de um retorno puro e simples às comunidades orgânicas do passado quanto a aceitação resignada do presente burguês ou seu

8 Parênteses de Löwy.

9 No Brasil, por exemplo, podemos citar Pedro Leão da Costa Neto e Jean Tible, respectivamente: NETO, P. L. C. Marx Tardio: notas introdutórias. (Artigo) Crítica Marxista, 2006, p. 80-95; TIBLE, J. Marx Selvagem. São Paulo: AnnaBlume, 2013, 242p.

10 LÖWY, M; SAYRE, R. Romantismo e Política. Rio de Janeiro: Paz e Terra, 1989, 98p.

11 LÖWY, M; SAYRE, R. Revolta e Melancolia: o romantismo na contracorrente da Modernidade. São Paulo: Boitempo, 2015, 287p. 
aprimoramento por meio de reformas" (LÖWY; SAYRE, 2015, p.102). Entretanto, o fato de Marx e Engels terem se utilizado de passagens de antropólogos evolucionistas como Maurer e Morgan, não se configura como uma perspectiva "romântica12" nem para Marx e Engels, e tampouco para Maurer e Morgan ${ }^{13}$. Há, também, que se considerar a contradição pela nomenclatura romântica exatamente no momento em que Marx e Engels demonstram maior atenção às comunidades primitivas não só européias, como também de outras localidades. Ainda que Marx e Engels tenham tido contato com Maurer e Morgan através de obras histórico-culturais ${ }^{14}$ que denotam o que revolucionários - principalmente Engels - conceituam posteriormente como "Comunismo Primitivo15", não é desse estágio que se trata os textos sobre a questão da Rússia. Portanto, uma diferenciação entre as comunidades primitivas e as comunidades rurais é especialmente necessária.

Podemos estabelecer como características das Comunidades Primitivas, as relações naturais de parentesco entre seus membros; a habitação comunal como base econômica da comunidade; e a propriedade comum e inalienável de terra cultivável associada com a produção comum e o repartimento do produto. Já as Comunas Rurais, ou comunidades agrícolas, possuem o primeiro agrupamento social de homens livres baseados não em laços de sangue (parentesco), mas sim em suas relações de vizinhança; suas casas e terrenos circundantes são de propriedade familiar; e a propriedade de terra também é comum e inalienável, porém é dividida periodicamente entre os membros da comuna num modelo de posse temporária familiar (SILVA, 2009, p. 94).

12 Para uma contraposição, vide: LUKÁCS, G. The destruction of Reason. UK: Merlin $\operatorname{Pr}$, 1980, 865p.

13 Vide: KRADER, Lawrence. Evolução, Revolução e Estado: Marx e o pensamento etnológico. In: HOBSBAWM, Eric. A História do marxismo, Vol. 1: O marxismo no tempo de Marx. Rio de Janeiro: Paz e Terra, 1979, p.435-438.

14 Vide principalmente: MARX, K. The Ethnological Notebooks. (Org: Lawrence Krader). Assen: IIVSGA, 1974, 454p; ENGELS, F. A origem da família, da propriedade privada e do Estado. Rio de Janeiro, Bestbolso, 2014, 223p.

15 Vide: ENGELS, Friedrich. A origem da Família, da Propriedade Privada e do Estado. Rio de Janeiro, Bestbolso, 2014, p.47; MARX, Karl; ENGELS; Friedrich. Manifesto Comunista. São Paulo, Boitempo, 1Ed. Revista, 2010, p.40. 
Dentre as diversas questões apresentadas no compilado Lutas de Classes na Rússia, a que podemos estabelecer como central pode ser resumida pela indagação levantada por Marx e Engels no prefácio de 1882 à edição russa do Manifesto Comunista (p.125): poderia a comuna rural russa - forma já muito deteriorada da antiga posse em comum da terra - transformar-se diretamente na propriedade comunista? Ou, ao contrário, deveria antes passar pelo mesmo processo de dissolução que constitui a evolução histórica do ocidente?

Marx não defendia a manutenção da comuna rural russa, mas sim, uma mudança em seu estágio de sociedade que não precisasse, necessariamente, passar pela experiência capitalista. Ou seja, as comunas rurais poderiam "trocar de pele sem precisar antes cometer suicídio" (p.112). A comunidade russa, para Marx, ocupava um lugar onde o horizonte era propício para uma evolução comunista, de modo que o olhar de Marx era de certa forma positivo, evidenciando que ela permanecia intacta numa circunstância onde o Capitalismo era predominante. A situação histórica da comuna rural russa para Marx é "sem igual", sendo uma experiência "única na Europa que se mantém não como ruína esparsa (...) mas como forma quase predominante da vida popular e espalhada por todo um imenso Império" (p.100). Para Marx, a comuna rural "é capaz de incorporar as conquistas positivas produzidas pelo sistema capitalista sem passar por seus 'forcados caudinos'” (p.100). Para que essa transformação aconteça, "é preciso que haja uma revolução russa (...) de resto, os detentores dos poderes políticos e sociais fazem o melhor que podem para preparar as massas para essa catástrofe" (p.100) - logo, só a revolução poderia "salvar a comuna russa". O caráter único da comuna ruralrussa retoma uma discussão também contemplada em O Capital, onde é exemplificado que a acumulação primitiva, tendo por base a expropriação de terras que antes pertencia ao produtor rural, "assume tonalidades distintas nos diversos países e percorre as várias fases em sucessão diversa e em diferentes épocas históricas" (MARX, 2013, p.787), distinção essa que dá o tom à peculiaridade russa.

A perspectiva de Engels sobre a Comuna Rural se deu de maneira diferente da adotada por Marx, no entanto. Na Literatura dos 
Refugiados $V$, Engels sugere que a única forma possível de sobrevivência da comuna russa é através de uma "revolução proletária na Europa Ocidental", devido ao fato de que, para o autor, a comuna russa caminhava naturalmente para sua dissolução (p.53). A perspectiva adotada por Engels evidenciava, sobretudo, a fragilidade das Comunas Rurais. O próprio posfácio de Engels, Questões Sociais na Rússia, já em 1894, parece confirmar que o autor desconsiderou a heterogeneidade da realidade social da Comuna, de modo a obscurecer suas especificidades, abordagem essa que Marx não deixou de sublinhar (MUSETTI, 2014, p.219). Ainda no prefácio da edição russa do Manifesto Comunista, texto posterior aos demais que tratavam propriamente da questão, Marx e Engels concluem respondendo a indagação supracitada. Com efeito, a conclusão de ambos se direciona a pensar que uma Revolução na Rússia deveria caminhar junto com a Revolução no Ocidente:

Hoje em dia, a única resposta possível é a seguinte: se a revolução russa constituir-se no sinal para a revolução proletária no Ocidente, de modo que uma complemente a outra, a atual propriedade comum da terra na Rússia poderá servir de ponto de partida para uma evolução comunista (MARX, ENGELS, p. 125).

Outra diferença de abordagem peculiar a Marx diz respeito à importância que o autor dá ao papel do Estado na dissolução dessa forma comunal de sociedade. Marx chega a afirmar que "o que ameaça a vida da comuna russa não é nem uma fatalidade histórica nem uma fatalidade teórica", mas sim, "a opressão por parte do Estado e a exploração pelos intrusos capitalistas que se tornaram poderosos, à custa dos camponeses, com ajuda do próprio Estado" (p.105). A utilização de "fatalidade histórica" foi motivada pela resposta a Veza Zasulitch, que menciona "a teoria da necessidade histórica", noção segundo a qual "todos os países do mundo passem (necessariamente) por todas as fases de produção capitalista" (p.80), novamente retomando a discussão já supracitada acerca da variabilidade da história.

Por fim, quando Marx e Engels citam "estágios" de sociedade, é importante mencionar que essa noção não se relaciona com um desenvolvi- 
mento linear dessas sociedades. É evidente que uma comuna rural pode se transformar em uma comunidade feudal, mas isso não quer dizer que essa comunidade tenha seguido seu "destino histórico". Isso também não significa que uma sociedade não possa passar por um processo de "evolução", porém, do ponto de vista do materialismo histórico, não se compreende como evolução uma sociedade que passa "necessariamente" pelos estágios primitivo, agrícola, feudal, capitalista e tem como horizonte o comunismo (MARX, 2006, p. 65-67). Assim, essa variação histórica não se trata de um etapismo linear, mas sim, de transformações que as sociedades estão propícias a ter, seja pelo "caminho" que seguiram as sociedades da Europa Ocidental, ou até outras possibilidades alternativas, como era o esperado dascomunas rurais da Rússia.

\section{REFERÊNCIAS}

LÖWY, M; SAYRE, R. Revolta e Melancolia: o romantismo na contracorrente da Modernidade. 1 ed ${ }^{16}$. São Paulo: Boitempo, 2015, 287p.

MARX, Karl; ENGELS, Friedrich. Lutas de Classes na Rússia. 1 ed. São Paulo: Boitempo, 2013, 164p.

MARX, Karl. Formações Econômicas Pré-Capitalistas. São Paulo: Paz e Terra, 2006, 136p.

. O Capital. Crítica da Economia Política. Livro 1: o processo de produção do capital. São Paulo: Boitempo, 2013. 894p.

MUSETTI, Felipe Ramos. Marx e Engels sobre a particularidade das lutas de classes na Rússia. Verinottio: revista on-line de filosofia e ciências humans, Belo Horizonte, v. 10, n. 20, p.216-219, out. 2014. Semestral.

SILVA, Rafael Afonso da. Marx e a questão Russa. Cadernos Cemarx, Campinas, v. 5, n. 1, p.89-102, ago. 2009.

16 Vale ressaltar que essa é a primeira edição da Boitempo, entretanto a Editora Paz e Terra já em 1993 publicou a primeira versão brasileira dessa obra. 